
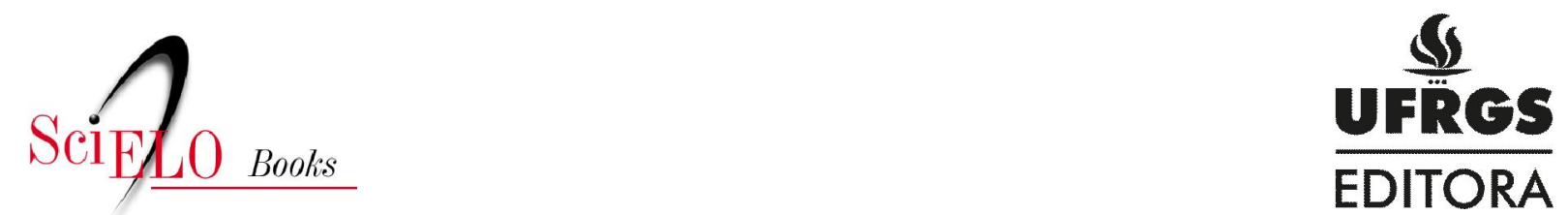

\title{
As disfunções do capitalismo na visão de Keynes e suas proposições reformistas
}

\author{
Fábio Terra \\ Fernando Ferrari Filho
}

\section{SciELO Books / SciELO Livros / SciELO Libros}

TERRA, F., and FERRARI FILHO, F. As disfunções do capitalismo na visão de Keynes e suas proposições reformistas. In: DATHEIN, R., org. Desenvolvimentismo: o conceito, as bases teóricas e as políticas [online]. Porto Alegre: Editora da UFRGS, 2003. Estudos e pesquisas IEPE series, pp. 345-373. ISBN 978-85-386-0382-5. Available from doi: 10.7476/9788538603825. Also available in ePUB from: http://books.scielo.org/id/8m95t/epub/dathein-9788538603825.epub.

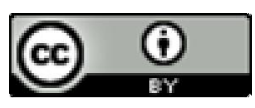

All the contents of this work, except where otherwise noted, is licensed under a Creative Commons Attribution 4.0 International license.

Todo o conteúdo deste trabalho, exceto quando houver ressalva, é publicado sob a licença Creative Commons Atribição 4.0.

Todo el contenido de esta obra, excepto donde se indique lo contrario, está bajo licencia de la licencia $\underline{\text { Creative Commons }}$ $\underline{\text { Reconocimento } 4.0 .}$. 


\section{As disfunções do capitalismo na visão de Keynes e suas proposições reformistas}

Fábio Terra

Fernando Ferrari Filho

\section{Introdução}

Com a recente crise econômica mundial, o debate sobre uma maior intervenção do Estado na economia voltou à "ordem do dia" com uma ressonância não observada desde meados dos anos 1970, quando, como decorrência do processo de estagflação, acadêmicos e policymakers passaram a preconizar o arrefecimento da intervenção estatal. No interim desse debate, a teoria econômica de John Maynard Keynes, declarada morta por Lucas (1980), foi novamente trazida ao centro das discussões por importantes economistas do chamado Novo Consenso Macroeconômico, dentre os quais Mankiw (2008) e Krugman (2009).

Neste particular, duas questões surgem: como Keynes apreendeu a realidade humana e social a ponto de teorizar sobre a importância da intervenção estatal para o alcance de uma dinâmica estável do sistema capitalista? Como Keynes concebia a administração da política econômica - isto é, a atuação econômica estatal - para que o sistema econômico incorresse em uma trajetória estável?

As pistas para a primeira resposta centram-se na própria forma pela qual Keynes concebeu a ciência econômica, como uma ciência moral. Enquanto tal, ela é uma ciência que lida com um elemento independente e determinante, o homem, que é idiossincrático em relação aos objetos das ciências naturais porquanto agente apto a alterar seu comportamento ao longo do tempo histórico, influenciando, assim, a sociedade que o 
circunda e, não obstante, influenciado por esta mesma sociedade. Logo, a teoria econômica deve preocupar-se em estabelecer sua epistemologia de forma a considerar as possibilidades ontológicas do homem, não somente para consigo, mas para com o todo no qual emergem suas ações.

Para Keynes, o agente econômico é, por natureza, incerto, porém livre para tomar suas decisões de investimento, sendo esta uma condição indispensável para a ampliação da sua riqueza. É neste cenário que Keynes aponta que a probabilidade não deve ser tratada como um cálculo baseado em frequências de eventos passados, mas como uma relação lógica e racional de se conhecer algo a partir da ausência de fontes de informação perfeitas. Não obstante, a própria trajetória social é incerta, uma vez que as consequências das decisões individuais afetam não somente os seus tomadores, mas os outros, de tal sorte que sempre há, na repercussão das decisões sobre o todo, alguma parcela que supera o esperado pelos tomadores de decisão. Somente compartilhando-se dessa concepção de organicidade entre o ser humano e a sociedade é que se sugere ser possível responder à segunda questão supracitada e compreender as proposições de política econômica em Keynes. Nesse sentido, as políticas econômicas keynesianas são fundamentais para mitigar as crises do sistema capitalista, caracterizadas por insuficiência de demanda efetiva ${ }^{1}$.

Tais proposições, por sua vez, são relacionadas à administração das políticas monetária e fiscal, notadamente essa, uma vez que impacta diretamente sobre a demanda efetiva do sistema econômico e, consequentemente, sobre a expectativa do agente tomador de decisão, qual seja, o empresário. Para Keynes, a política monetária deve viabilizar a precificação dos ativos em prol de inversões produtivas, enquanto a política fiscal deve estabelecer um acordo tácito entre Estado e investidores. Em suma, as políticas econômicas devem servir como mantenedoras e incentivadoras das expectativas dos empresários, balizando suas esperanças sobre a demanda efetiva por seu produto e fornecendo-lhes peso aos seus argumentos, a fim de lhes oferecer melhores estados de confiança sobre o tempo futuro no qual suas decisões se efetivam.

\footnotetext{
${ }^{1}$ Conforme o princípio da demanda efetiva (PDE), os níveis de renda e emprego aumentam se, e somente se, a renda esperada pelo emprego adicional for maior que a renda necessária. Em outras palavras, a demanda efetiva representa o valor do produto que as empresas acreditam que produzirá lucro máximo face suas expectativas sobre a posição da demanda agregada. Para maiores detalhes, veja Keynes (1964, cap. 3).
} 
Diante do exposto, o objetivo deste capítulo é mostrar como a visão de mundo de Keynes se relaciona com suas proposições de política econômica e justifica sua teorização sobre a atuação econômica estatal. Para tanto, a seção 2 apresenta, inicialmente, a concepção de Keynes da sociedade como uma unidade orgânica. Em seguida, são apresentadas a ideia central da teoria da probabilidade de Keynes e a sua filosofia da prática. Na seção 3, apresentam-se as proposições keynesianas de política econômica, especificamente as políticas monetária e fiscal. Por fim, a seção 4 apresenta as considerações finais do capítulo.

\section{A visão de mundo em Keynes}

\subsection{A unidade orgânica}

As percepções de Keynes acerca da conduta racional do homem apropriaram-se da noção de unidade orgânica do filósofo George Moore (contemporâneo de Keynes em Cambridge), conforme se observa no artigo "My Early Beliefs", de 1938 (Collected Wrtitings of John Maynard Keynes, X, 1972b) ${ }^{2}$, que expõe o pensamento de Keynes quando de sua chegada em Cambridge, no início dos $1900^{3}$. A unidade orgânica é caracterizada pelo fato de o indivíduo não formar suas convenções e valores apenas com base em sua razão, mas relacionando-a tanto com as partes quanto com o todo ao qual ele está circunscrito. A consciência do indivíduo, desta forma, construirá "valores dependentes, de acordo com o princípio da unidade orgânica, do estado das coisas como um todo, que não podem ser utilmente analisadas em nível [somente] das partes" (CWJMK, X, 1972b, p. 436).

No que interessa à ciência econômica, a unidade orgânica relaciona o homem e a sociedade. Nesse sentido, para Keynes, a principal rela-

\footnotetext{
${ }^{2}$ De agora em diante, as referências oriundas dos volumes do "The Collected Writings of John Maynard Keynes” serão sinalizadas pelo acrônimo CWJMK seguido do volume e do ano. As demais referências de Keynes serão denotadas apenas pelo ano da edição da obra. ${ }^{3}$ Embora sucinto, o artigo My Early Beliefs deu corpo a toda uma literatura especializada nos debates sobre a influência da filosofia em Keynes e sobre o chamado "keynesianismo filosófico". Para mais, veja Rotheim $(1989,1990)$, Davis $(1989,1990)$, Bateman e Davis (1991), Skidelsky (1999) e Andrade (2000).
} 
ção orgânica é a travada entre uma categoria específica de agente, qual seja, o empresário (ou investidor) e a sociedade na qual ele atuará em busca da ampliação de sua riqueza monetária ${ }^{4}$. A medida que é esta categoria específica de homem, o empresário, a que detém a capacidade de empregar recursos monetários em bens de capital, máquinas e equipamentos, será ela a responsável pelo emprego dos demais indivíduos, criando assim, renda e, consequentemente, ampliando a riqueza social. Contudo, a unidade orgânica implica que o lucro monetário do empresário dependerá do comportamento dos outros agentes, especificamente, da demanda efetiva social pela sua oferta individual.

Em contraste, como alerta Keynes em sua The General Theory of Emploment, Interest and Money (doravante GT), o sucesso do empresário neoclássico, não suposto como pertencente a um todo em unidade orgânica, não está condicionado à possibilidade de ocorrência de demanda efetiva pela sua oferta. A Lei de Say, rejeitada por Keynes, garante que toda oferta promova sua própria demanda, pois toda decisão individual de produzir é motivada pela utilidade que será alcançada ao se trocar os frutos da produção por algum outro produto pretendido. Assim sendo, consoante a Lei de Say, o preço de demanda agregada, isto é, o produto efetivamente demandado, equivale exatamente ao preço de oferta esperado pelos empresários, para todo e qualquer nível de emprego (Keynes, 1964). Toda expansão no emprego, com respectiva ampliação da oferta agregada, cria uma elevação em mesma magnitude na demanda agregada. Não há, por parte do empresário, uma expectativa de demanda, mas uma demanda determinada pela própria oferta. Logo, a insuficiência de demanda efetiva é uma situação inexistente, que implica em todo e qualquer desemprego ser de natureza voluntária. Nas palavras de Keynes,

[...] isto quer dizer, a demanda efetiva, ao invés de ter um único valor de equilíbrio, comporta uma série infinita de valores todos igualmente admissíveis; e que o volume de emprego é indeterminado [...]. Então, a lei de Say, segundo

\footnotetext{
${ }^{4}$ Não é por demais salientar que, segundo Keynes "o empresário não está interessado no montante de produto, mas no montante de moeda que lhe será partilhado. Ele expandirá sua produção, pois espera, ao fazê-lo, aumentar seu lucro monetário" (CWJMK, XXIX, 1979, p. 82). Isso define, para Keynes, uma economia empresarial ou monetária da produção.
} 
a qual o preço de demanda agregada da produção em conjunto equivale ao preço da sua oferta agregada para todo volume de produção, equivale à proposição de que não há obstáculo para o pleno emprego. (Keynes, 1964, p. 26).

Sendo esse o modus operandi das forças de oferta e demanda no arcabouço teórico clássico, que conta ainda com a sinalização de preços no mercado oferecendo toda informação necessária à melhor alocação daquilo que se deve produzir e demandar, não há surpresa na interação entre as partes e entre a parte e o todo. Há, na verdade, uma perfeita simetria, com ajustes instantâneos entre os desejos de demanda e a oferta de bens e serviços. Além disso, sob tal lógica, a ampliação do nível de emprego e renda da sociedade depende apenas da concorrência entre os empresários que, ao ampliarem a demanda por trabalhadores, aumentam os salários reais e fazem com que a desutilidade marginal do trabalho torne-se custosa a ponto de fazer com que o nível de desemprego se reduza constante e voluntariamente. A competição empresarial, assim, levará o emprego a seu nível máximo em que a oferta torna-se inelástica. Pela validade da Lei de Say, a trajetória até a indisponibilidade de recursos voluntariamente ociosos é sempre estável, isto é, sem que existam pessoas desejosas de trabalho que estejam dele involuntariamente desocupadas.

Keynes, ao refutar a Lei de Say ${ }^{5}$, afirma que o pleno emprego apenas ocorrerá quando a totalidade das propensões individuais a consumir somada à totalidade dos incentivos individuais a investir se combinarem de uma forma que impeça qualquer discrepância entre o investimento corrente e o preço de oferta da produção deduzido do que a sociedade demandou em consumo. Nesse cenário, Keynes (1964, p. 28) argumenta que, diferentemente do que apregoa a Lei de Say, a demanda efetiva correspondente ao pleno emprego somente acontecerá por "acidente ou desígnio".

Dessa maneira, a realidade social como uma unidade orgânica cria a dificuldade para que as intenções individuais sejam acertadas ao ponto do alcance do pleno emprego. O organicismo social é a concepção

\footnotetext{
${ }^{5}$ A refutação da Lei de Say por Keynes foi de tal ordem que, segundo Kates (1992: 191) "a frase que ficou conhecida como a Lei de Say são as palavras introduzidas por Keynes, quais sejam, 'a oferta cria sua demanda'”. Para uma reinterpretação da validade da referida Lei e, inclusive, para uma reapresentação das críticas de Keynes à Lei de Say - e dos efeitos delas sobre a teoria econômica -, veja: Kates (1992).
} 
de que o resultado social das livres ações individuais não é um mero somatório das ações individuais, mas é sempre algo que se atinge além daquilo que é pretendido pelo indivíduo ao agir ${ }^{6}$. Assim,

[...] um sistema orgânico na teoria econômica de Keynes não é viciar um indivíduo em favor de algum todo independente, mas é o reconhecimento de que a natureza do indivíduo bem como sua percepção de si mesmo são funções de, e mudam com, suas interações com outros indivíduos. (Rotheim, 1989-1990, p. 322).

À medida que as ações individuais repercutem de formas inesperadas e não ocorrem as possibilidades coeteris paribus de ação de todos os outros indivíduos, a sociedade orgânica é incapaz de ser apreendida pelos indivíduos. Dessa forma, o processo de conformação do todo, a todo tempo, traduzir-se-á aos indivíduos como algo que lhes implicará novas percepções sobre o ambiente que lhes circunda. Nesse contexto dinâmico, “[...] ao reajustarem as estratégias de ação, os agentes também alteram o contexto e as condições em que atuam [...] os agentes se adaptam ao mundo - o padrão agregado - por eles cocriado" (Cardoso; Lima, 2008, p. 15).

Novamente em contraposição à teoria neoclássica, se ela postulasse como um dos seus princípios a unidade orgânica, seu indivíduo utilitarista necessitaria ter em sua função-utilidade variáveis explicativas representativas das funções-utilidade de todos outros indivíduos. Somente nessas condições o equilíbrio geral neoclássico seria mantido. Caso contrário,

[...] pode ocorrer de duas partes [...] não estarem carregando suas intuições para alcançarem precisamente o mesmo objetivo e, por conta do princípio da unidade orgânica, uma bem pequena diferença nos objetivos pode produzir uma grande diferença no resultado (CWJMK, X, 1972b, p. 437) ${ }^{7}$.

\footnotetext{
${ }^{6} \bar{E}$ importante esclarecer que "além" significa, conforme utilizado na passagem acima, um resultado diverso - podendo ser quantitativa ou qualitativamente maior ou menor do que o esperado pelo agente.

${ }^{7}$ Não é por menos que, “estávamos [Keynes e seus contemporâneos em Cambridge] entre os primeiros de nossa geração, às vezes sozinhos em nossa geração, a escapar da tradição Benthamita [utilitarista]" (CWJMK, X, 1972b, p. 445).
} 
Essa dinâmica de reciprocidade causal entre homem e sociedade, em que os efeitos da ação humana guardam resultados sociais imprevisíveis e em que esses resultados sociais impactam sobre o modo pelo qual o homem - agente social - compreende o mundo, tem como uma de suas mais relevantes consequências a "existência de uma incerteza radical" (Skidelsky, 1999, p. 109).

A incerteza está sempre presente em função da incapacidade do homem em apreender o todo no qual ele está inserido. Porém, o homem é criativo, de modo que o destino do mundo não se configura como algo a ser desvelado, mas criado por ele. Assim, as decisões de ação dos agentes, a todo instante, construirão trajetórias histórico-institucionais para a sociedade e, não obstante, resultarão em contextos não plenamente cognoscíveis. Nesse particular, não há a possibilidade de se conhecer, no presente, o futuro, pois não há a possibilidade de se definir e calcular tudo aquilo que a criatividade humana e sua interação criativa podem erigir (Skidelsky, 1999). Nas palavras de Carvalho (2003, p. 180), “o caminho é criado pelo caminhante ao caminhar, mas nem todas as trilhas podem ser abertas, ainda que não se saiba com antecedência quais realmente podem ser proficuamente exploradas".

Inobstante a incerteza radical acerca do futuro, não se pode desconsiderar o tempo como um elemento central na visão de mundo de Keynes, como destacam alguns economistas pós-keynesianos ${ }^{8}$. Consoante Carvalho (2003), o tempo deve ser analisado de duas formas: expectacional e histórica. No primeiro, a incerteza é elemento sine qua non, pois é devido à ocorrência dela que se forma uma expectativa, e não uma antecipação certa, do futuro. É por não se saber como se comportarão o todo e as partes em uma unidade orgânica que os agentes esperam determinados resultados. Por sua vez, o tempo histórico refere-se à irreversibilidade temporal. As conjunturas sociais e suas percepções por parte dos indivíduos alteram-se de forma crucial na dinâmica da unidade orgânica. Assim, o tempo histórico implica trajetória histórico-institucional futura diversa do contexto presente, porém composta a partir deste. Não obstante, tal trajetória futura é irreversível ao presente do qual emana.

${ }^{8}$ Para referências, veja: Robinson (1972), Eichner e Kregel (1975) e Davidson (1978; 1991a), dentre várias outras. 
Neste particular, acompanhando Davidson (1991b), ocorrerá, no tempo e no espaço probabilísticos, a não ergodicidade tanto dos dados resultantes das ações humanas quanto destas próprias ações. A apuração intelectual do conjunto de variáveis que cada indivíduo considera relevante para decidir agir pode ser bastante díspar ao longo do tempo histórico, impossibilitando a construção de uma formulação estatística que traga, no momento de decisão presente, os cálculos corretos das possíveis, em termos probabilísticos, consequências futuras. A ergodicidade, por isso, é uma hipótese não aplicável à ciência econômica, pois um de seus objetos centrais, o homem, não é uma medida invariável como os objetos das ciências naturais, mas uma medida variável. Dessa forma,

[...] eu também gostaria de enfatizar fortemente o ponto de que a economia é uma ciência moral [...]. Eu devo adicionar que ela lida com motivações, expectativas, incertezas psicológicas. Deve-se estar constantemente em guarda contra tratar o material [de estudo da ciência econômica] como constante e homogêneo. É como se pensar que a queda da maçã ao chão dependa dos motivos da maçã: se a ela vale à pena cair no chão, e se o chão deseja que a maçã caia (CWJMK, XIV, 1973b, p. 300).

Keynes considera a ciência econômica como uma ciência moral por crer que o homem é o agente social e criativo. Suas motivações, expectativas, o levam a atuar socialmente, ainda que enfrentem "o fato dominante da vida [...] a incerteza fundamental e incontornável que cerca o futuro" (Carvalho, 2003, p. 176). Imerso no sistema capitalista, definido por Keynes como a "economia monetária da produção", somente arriscando-se ante o inalcançável futuro poderá ter o homem, agindo enquanto investidor, maior poder de comando sobre a riqueza social.

\subsection{A teoria da probabilidade e a filosofia da prática}

Para compreender como se processa a ação humana diante do incerto contexto no qual se vive, entra em cena a teoria da probabilidade de Keynes, exposta em seu livro “A Treatise on Probability", de 1921 ${ }^{9}$. De forma

\footnotetext{
${ }^{9}$ Keynes, em My Early Beliefs, destaca como a unidade orgânica de Moore foi importante para que ele desenvolvesse sua teoria da probabilidade. Para mais, veja Keynes (CWJMK, X, 1972b).
} 
inovadora em relação aos padrões de teóricos sobre a probabilidade em vigor no início dos $1920^{10}$, Keynes propôs uma teoria da probabilidade não ancorada em bases quantitativas: "a probabilidade é o estudo das bases que nos levam a termos em mente, racionalmente, a preferência em uma crença a expensas de outra" (CWJMK, VIII, 1973a p. 106) ${ }^{11}$.

Consoante Carvalho (1988), a preocupação de Keynes em observar como se pode qualificar uma determinada relação entre variáveis enquanto mais ou menos confiável, ao invés de mensurá-la e determiná-la enquanto mais ou menos provável, decorre da sua intenção de compreender os parâmetros que comovem um indivíduo a uma tomada de decisão: "Keynes primeiramente aproximou-se da probabilidade na busca por critérios que suportassem as decisões práticas" (Carvalho, 1988, p. 67).

A tomada de decisão do indivíduo é, segundo a teoria da probabilidade de Keynes, resultado de um processo de duas etapas. A primeira diz respeito ao conjunto de informações que um indivíduo elenca e apreende imediata ou diretamente. A essas informações Keynes denominou premissas e elas conformam o que é conhecido pelo indivíduo objetiva e diretamente: é o conhecimento direto. A segunda etapa, subjetiva e mediata, configura-se em como as premissas, ou seja, o conhecimento direto do indivíduo, são por ele raciocinadas até se transformarem em proposições ou argumentos. Portanto, na segunda etapa, o sujeito elabora racionalmente seu conhecimento direto, transformando-o em uma determinada proposição.

Assim sendo, a probabilidade em Keynes define-se enquanto

[...] dado o corpo de conhecimento direto que constitui nossas premissas básicas, essa teoria [da probabilidade] nos diz quais crenças racionais, certas ou prováveis, podem ser derivadas por proposições válidas, de nosso conhecimento direto (CWJMK, VIII, 1973a, p. 4).

\footnotetext{
${ }^{10}$ Nesta época, início dos anos 1920, a "agenda de pesquisa" sobre probabilidade se centrava na apuração estatística das distribuições de frequência. Para mais, veja Carvalho (1988) e Skidelsky (1999).

${ }^{11}$ Ciente de que sua perspectiva sobre probabilidade enfrentaria severas resistências e que era preciso, em vista disto, um trabalho de persuasão sobre a comunidade científica, Keynes (CWJMK, X, 1972b, p. 438) argumenta: "consideramos tudo isto [a sua teoria da probabilidade] como inteira e caracteristicamente racional e científica. Como qualquer outro ramo da ciência, não é nada mais do que a aplicação da lógica e da análise racional ao material apresentado como dados à nossa sensibilidade”.
} 
A probabilidade em Keynes envolve o grau em que se pode crer racionalmente numa relação lógica travada entre um conjunto de premissas conhecidas e apreendidas pelo indivíduo e as proposições que se lhe são permitidas concluir a partir do raciocínio que ele faz, imbuído das referidas premissas. Em outros termos, a probabilidade para Keynes refere-se ao grau em que o indivíduo racionalmente crê que suas premissas possam tornar-se argumento. Isto é, por sua vez, qualificar a força com que um agente racionalmente acredita que sua proposição poderá tornar-se concretude e, por conseguinte, conhecimento estabelecido e hábil a ser imediatamente absorvido por outros indivíduos.

O critério elencado por Keynes para validar essa forma de conceber a probabilidade é a lógica, entendida como as regras que permitem a sistematização e a verificação da pertinência de argumentações, tornando-as válidas ${ }^{12}$. A possibilidade de premissas tornarem-se argumento com algum grau de crença racional de ser provável ou certo decorre do último "designa[r] apenas uma determinada combinação de elementos, que não é um simples amontoado, mas sim uma articulação cujo caráter lógico pode ser apreendido e claramente mostrado" (Moreno, 2006, p. 23, itálicos originais).

Um empresário em busca do lucro monetário, somente investe após raciocinar, baseado em determinadas premissas conhecidas por ele. Por exemplo, caso estas premissas o informassem que a cultura da localidade na qual ele se encontra e investirá condena radicalmente a ingestão de bebida alcoólica, sua crença racional lhe conduziria a ter como muito pouco confiável o lucro monetário, caso ele investisse em uma fábrica de bebida alcoólica. Em contraposição, em uma localidade em que os habitantes são habituados a consumir bebida alcoólica, as proposições do empresário que o fazem decidir produzir a referida bebida são mais confiáveis de se tornarem concretas.

\footnotetext{
${ }^{12}$ É importante ressaltar que, conforme Keynes (CWJMK, X, 1972b), dentre seus convivas em Cambridge estavam Bertrand Russel e Ludwig Wittgenstein, dois expoentes, no século XX, da lógica filosófica, ramo da filosofia que se dedica à compreensão dos fundamentos da lógica constituinte do pensamento e, por consequência, do conhecimento. Keynes, que frequentava Lectures destes filósofos, tinha a consideração necessária com a pertinência lógica de suas teorizações. Para mais sobre as relações entre Keynes e os filósofos de Cambridge, veja Bateman e Davis (1991) e Coates (1996).
} 
Ao investir, um empresário crê em elevado grau que suas proposições são certas. Principalmente, o empresário crê, no presente, que aquilo que ele espera, enquanto provável no futuro, efetive-se. A isto, Keynes chamou, na GT de estado de confiança do empresário (Keynes, 1964, cap. 12). O estado de confiança é justamente o grau de crença racional do empresário sobre a validade futura de suas proposições e decisões presentes.

Neste ponto é importante ressaltar, conforme fazem Cardoso e Lima (2008), que a habilidade criativa do homem, o uso constante desta capacidade, bem como a imprevisibilidade do destino das transformações sociais, não significam para a sociedade o caos completo e, para o homem, a inação e a desconfiança generalizada. Embora dinâmica, a trajetória histórica da unidade orgânica é percebida pelos indivíduos como apresentando uma série de regularidades, motivadas, principalmente, por certas regras ou convenções tacitamente incorporadas pelos agentes e que se configuram em premissas das quais se supõem maiores graus de crença racional ${ }^{13}$ (Bateman; Davis, 1991). Nesse sentido, essas convenções, que podem até mesmo ser materializadas em contratos entre as partes envolvidas, funcionam para manter determinadas percepções de regularidade, pois,

[...] na prática, concordamos, geralmente, a recorrer a um método que é, na verdade, uma convenção. A essência desta convenção - embora ela nem sempre funcione de forma tão simples - reside em se supor que a situação existente dos negócios continuará por tempo indefinido (Keynes, 1964, p. 152, itálico original).

A trajetória social se altera com constância e de forma imprevisível, mas os indivíduos são capazes de jogar com a transformação e sobreviver a ela, pois absorvem e respeitam determinadas regras convencionais que se espraiam pela sociedade. A título de ilustração, Keynes argumenta que

\footnotetext{
${ }^{13}$ Um exemplo de convenção tacitamente assumida, conforme Rotheim (1989-1990, p. 324), pode ser observado "no estabelecimento da oferta de trabalho em termos monetários [...] [que] [...] tem o efeito de manter os preços monetários estáveis, o que, por sua vez, adiciona um elemento de confiança às expectativas de longo prazo dos empresários".
} 
[...] a iniciativa individual somente será adequada quando a previsão razoável for secundada e sustentada pelo dinamismo, de tal maneira que a ideia de prejuízos finais [...] é repelida do mesmo modo que o homem saudável repele a probabilidade de sua morte (Keynes, 1964, p. 162).

Para salientar a importância das convenções, cabe ressaltar o extremo pessimismo com que Keynes enxergava o modus operandi da Bolsa de Valores de Nova York nos anos 1920, visto que suas operações se tornaram voltadas à tentativa dos seus participantes em apossarem-se da maior remuneração mantendo-se nas posições mais líquidas possíveis. Dessa forma, surgiu uma forma de convenção de curtíssimo prazo, em que os corretores da Bolsa não mais baseavam suas expectativas acerca do futuro das empresas listadas na Bolsa, mas naquilo que eles apostavam que seria a expectativa média dos operadores sobre o futuro de alguma empresa. Assim, o objeto de antecipação e aposta deixou de ser o futuro de um investimento e passou a ser a expectativa convencionada pelos operadores da Bolsa, isto é, a psicologia de curto prazo do mercado de ações (Keynes, 1964). Não obstante, desta referida deturpação imputada sobre o objetivo da Bolsa de Valores surge ainda a possibilidade de uma convenção peremptória soerguer e eliminar intempestivamente uma determinada convenção. A este fenômeno a literatura econômica, especialmente a de inspiração keynesiana, denominou comportamento de manada. À ação destes atores do mercado financeiro, pouco preocupados com investimentos efetivamente produtivos como forma melhor de ampliação da riqueza social, Keynes (1964, p. 158) denominou “especulação".

Ao decidir realizar um investimento pioneiro, que se concretizará no longo prazo, o empresário é motivado pela sua expectativa de o futuro repetir a conjuntura que ele presentemente raciocina como favorável ao investimento e à recompensa do lucro monetário. Nos tempos histórico e expectacional que o separam da realização de seu investimento, o empresário usa de seu dinamismo e de suas novas apostas baseadas em suas crenças racionais atualizadas para promover, no curto prazo, ações que ele acredita levarem ao resultado que ele espera no longo prazo. Isto, por sua vez, é diferente das expectativas e decisões relacionadas à produção tomadas sobre investimentos devidamente concluídos. Sobre estas incidem expectativas de curto prazo que comovem o empresário a produzir uma maior ou menor quantidade (Keynes, 1964). 
Ambas as expectativas e decisões, de produção e de investimento, são fundamentais para a ampliação do emprego, da renda e da riqueza social. Porém, são as expectativas e decisões de longo prazo, construtoras de novos investimentos, as mais importantes para a ampliação da riqueza social, ainda que sejam as de base expectacional mais precária. São elas as principais mobilizadoras de recursos para a expansão do estoque de capital social, ampliando, dessa forma, o potencial de produção de riqueza e amainando a discrepância entre os níveis de consumo e de produto da sociedade.

Para os empresários, assim como para qualquer indivíduo decidindo como agir, no curto e no longo prazos, a presença de convenções faz com que as premissas em que eles se inspiram para proporem seus investimentos tenham maior grau de crença racional. Não apenas as convenções, mas também conhecimento direto - como o volume existente dos vários tipos de capital, a intensidade da procura atual, os contratos com operários e com fornecedores - fomentam ao investidor um conjunto ampliado de premissas sobre as quais ele baseará sua decisão. À medida que o conjunto de premissas em que se respalda o indivíduo se expandir, ampliar-se-á o peso do seu argumento, ou seja, a confiança em sua proposição, em sua decisão. Então, o peso do argumento é o crescimento da quantidade de conhecimento direto que se possui e que viabiliza a expansão do grau da crença racional do indivíduo em determinado argumento, muito embora não implique que o futuro será mais provável ou certo. É sobre a confiança em um argumento que pesa o volume maior de premissas, não sobre a probabilidade de um dado futuro (Cardoso; Lima, 2008).

Os empresários, em suas iniciativas de ampliar sua riqueza, arriscam recursos monetários no presente, crendo na consecução de suas proposições no futuro. Tal aposta, embora racional, "depende mais do otimismo espontâneo [...] do nosso entusiasmo - como um intuito espontâneo de agir, em vez de não fazer nada”. Ademais, conforme argumenta Keynes, o investimento ocorre, pois, em seu animal spirits: "o empreendedor procura convencer a si próprio de que a principal força motriz de sua atividade reside nas afirmações de seu propósito, por mais ingênuas e sinceras que possam ser" (Keynes, 1964, p. 161-162).

A riqueza social somente será aumentada se o ânimo dos empresários validarem suas decisões de mobilização de recursos monetários em novos empreendimentos. O empresário, contudo, é participante de 
uma unidade orgânica transeunte, o que afeta seu ânimo e suas decisões. Dessa forma, o produto e o volume de emprego são dependentes das percepções que o empresário detém no bojo da trajetória histórica da sociedade. Baseado nesta construção filosófica sobre a relação homem-sociedade e sobre as bases motivacionais da ação humana, Keynes provoca uma revolução teórica na ciência econômica. Para ele, a verdadeira liberdade individual não advém da livre ação do indivíduo no mercado e da autorregulação econômica que pretensamente emana disso. Essa concepção, inclusive, pode conduzir a processos de eliminação das liberdades individuais.

Em um contexto de unidade orgânica, a trajetória social pode ocorrer de uma forma tal que provoque uma ampla redução dos elementos concretos que servem de premissas às proposições e decisões dos agentes no mercado. Sistemas econômicos de pleno laissez-faire estão fortemente inclinados a mudanças inopinadas nas convenções e, também, no peso dos argumentos dos empresários. Para Keynes, não se pode saber quais são as percepções e proposições de todos os indivíduos, ao ponto de o bem comum ser atingido pelo mercado livre. A plena liberdade individual só será promovida, mantida e ampliada se existir a coordenação da ação individual, uma vez que se tenha ciência das bases precárias das quais emerge a ação humana. Em outros termos,

[...] porém, acima de tudo, o individualismo, se puder ser purgado de seus defeitos e abusos, é a melhor salvaguarda da liberdade pessoal, no sentido de que amplia mais do que qualquer outro sistema o campo para o exercício das escolhas pessoais (Keynes, 1964, p. 380).

A coordenação do sistema econômico não se trata de uma planificação da economia, pois isso transferiria a própria ação empresarial aos entes no comando da planificação. Com efeito, a coordenação se trata de uma ação de política econômica em sintonia fina com aquilo que for necessário para cooperar com a iniciativa privada (Keynes, 1964). O Estado é o ente social capaz de reunir o maior número de informações disponíveis e, sem embargo, é o mais influente ator social. Cabe-lhe, portanto, coordenar a atividade econômica.

Sobretudo, as proposições de política econômica coordenadoras da atividade econômica em Keynes não decorrem apenas de sua visão so- 
bre o homem e da forma pela qual ele se relaciona com a economia e a sociedade. Decorre da responsabilidade prática que há de se ter, uma vez que se tenha em mente tal visão de mundo e que se esteja consciente, portanto, dos principais problemas do sistema capitalista e dos riscos da instabilidade perene que lhe acometem. Compreender as bases sobre as quais opera o sistema capitalista é um convite a nele atuar a fim de superar suas mazelas. Essa é a filosofia da prática em Keynes, ressaltada pelas palavras de Andrade (2000, p. 86), “[...] por ser uma teoria da ação, e não da contemplação, a teoria do conhecimento de Keynes é voltada para as possibilidades de transformar a realidade por meio de mudanças das crenças e opiniões acerca da realidade".

\section{As políticas monetária e fiscal em Keynes}

Ao produzir ciência econômica, uma das preocupações fundamentais de Keynes foi compreender e propor medidas para mitigar crises de insuficiência de demanda efetiva e suas repercussões em termos de instabilidade cíclica nos níveis de produto e emprego (Ferrari Filho, 2006). Como proposição sumária, Keynes afirmava que as flutuações no sistema capitalista decorrem do fato de que "[...] uma economia monetária [...] é essencialmente uma economia em que mudanças de pontos de vista sobre o futuro são capazes de influenciar o volume de emprego" (Keynes, 1964, p. 4, itálicos adicionados).

A característica essencial de uma economia monetária é que a moeda não é apenas um meio de troca, mas é um ativo capaz de resguardar as alterações nas mudanças de pontos de vista sobre o futuro, pois reserva poder de comando sobre a riqueza social ao longo do tempo, possuindo liquidez máxima para saldar tanto transações à vista quanto contratos diferidos no tempo. Nesse sentido, a depender da forma pela qual a preferência pela liquidez dos empresários for condicionada pelas proposições esperadas deles sobre o futuro, induzir-se-ão "movimentos de substituição das formas de riqueza, aumentando ou diminuindo a demanda por ativos reprodutíveis e, assim, aumentando ou diminuindo a renda gerada na produção de novos itens" (Carvalho, 1994, p. 47).

Para suavizar o ritmo das mudanças de pontos de vista por parte dos empresários, e em consonância com a filosofia da prática de que parti- 
lhava, Keynes propôs, em sua GT, uma nova filosofia social para resolver "os principais problemas da sociedade econômica em que nós vivemos [que] são o desemprego e a arbitrária e desigual distribuição da renda e da riqueza" (Keynes, 1964, p. 372). Neste sentido Keynes pretendeu que

[...] o Estado deverá exercer uma influência orientadora sobre a propensão a consumir, seja através de seu sistema de tributação, seja, em parte, por meio da fixação da taxa de juros e, em parte, talvez, recorrendo a outras medidas [...] Eu entendo, portanto, que uma socialização algo ampla dos investimentos será o único meio de assegurar uma situação aproximada de pleno emprego (Keynes, 1964, p. 378, itálicos adicionados).

A partir das proposições da filosofia social a que poderia levar à GT, a requerida orientação estatal propugnada por Keynes expressava-se por meio daquilo que define, em última instância, o norte econômico de qualquer sistema social: a política. Assim, Keynes define o problema político, notadamente o econômico, como carecendo da combinação de

[...] três elementos: eficiência econômica, justiça social e
liberdade individual. O primeiro precisa de crítica, pre-
caução e conhecimento técnico; o segundo, um espírito
não egoísta e entusiasta que ame o homem médio; o ter-
ceiro, tolerância, amplitude, apreciação da variedade e da
independência, que prefere, sobretudo, oferecer oportu-
nidade progressista ao excepcional e ao aspirante (Keynes
apud Minsky, 1986, p. 8).

Nesse sentido, quais políticas econômicas devem ser instituídas para se mobilizarem os recursos desviados da produção? Para Keynes, nada mais do que as políticas macroeconômicas convencionais - monetária e fiscal ${ }^{14}$ -, uma vez que políticas em nível microeconômico poderiam gerar distorções, privilégios e ineficiências. Atuando-se em âmbito mais generalizado,

\footnotetext{
${ }^{14}$ É importante ressaltar que no Capítulo 24 da GT, Keynes ressalta, além das políticas tradicionais, a política de renda. Para maiores informações sobre políticas macroeconômicas, não necessariamente monetária e fiscal, em uma perspectiva keynesiana, veja Carvalho (1999) e King (2003).
} 
como o macroeconômico, poderia permitir-se a atuação mais abrangente possível da iniciativa privada, evitando-se concentrações de oportunidade e de renda. Quais seriam os papéis das referidas políticas?

\subsection{A política monetária}

À política monetária caberia realizar, por meio da administração da taxa de juros básica da economia, o alinhamento dos preços relativos dos ativos passíveis de investimento. Para Keynes (1964), todos os ativos possuem intrinsecamente uma taxa de juros (de retorno). Pela comparação entre as remunerações factíveis de escolha, os agentes podem destinar seus recursos - caso lhes seja mais vantajoso em termos de liquidez, custo de carregamento e quase-renda - a ativos não suscetíveis de reprodução fabril. Isso ocorrerá principalmente quando os investimentos produtivos realizados no passado tornarem-se estoques involuntários e expectativas frustradas.

A taxa de juros básica da Autoridade Monetária (AM) deveria ser de pleno conhecimento por parte dos agentes econômicos e estar em um patamar considerado pelos referidos agentes como normal, dentro de suas convenções, pois como aponta Carvalho (1999, p. 275, itálicos adicionados) "as pessoas formam uma expectativa da taxa de juros normal e esperam que as taxas atuais gravitem ao seu redor". Todavia, como existe um desconhecimento acerca do futuro, a taxa de juros é sempre alvo de tentativas de antecipação por parte dos agentes econômicos, que a ela se atentam para não incorrerem em elevados custos de oportunidade de investimento.

Em seu Treatise on Money (CWJMK, V, 1971) Keynes, seguindo a tradição de Wicksell, segundo a qual há uma taxa de juros natural e uma taxa de juros de empréstimos (mercado), também define a existência de duas taxas de juros, a natural e a de mercado. A primeira é a taxa de juros que mantém a igualdade entre poupança e investimento e se aproxima da taxa de juros normal, esperada pelos agentes econômicos. A segunda é formada pelas taxas dos empréstimos de curto prazo, bank rate, e de longo prazo, bond rate. Além disso, Keynes pressupõe ainda duas esferas de circulação econômica, a industrial e a financeira. Na primeira esfera de circulação, transacionam-se ativos de capital, enquanto, na segunda esfera de circulação, ativos monetários e financeiros são transacionados. 
Assim, quando a taxa de juros de mercado for superior à taxa de juros natural, será mais vantajoso ao investidor migrar da circulação industrial para a financeira, provocando um aumento da poupança em relação ao investimento ${ }^{15}$. Nessa situação, a ação do banco central propícia à circulação industrial, ou seja, ao investimento produtivo, deve ser a busca pela coincidência entre as taxas natural e de mercado. Portanto, a taxa de juros da AM torna-se uma premissa, um conhecimento direto, em que os empresários a tomam como referência para decidir em que investir. Dessa maneira, a qualquer desconfiança de oscilação na taxa de juros em torno daquilo que se considera normal, haverá modificações na destinação dos gastos dos investidores (empresários).

Carvalho (1994) chama a atenção para uma ilustração válida para a representação de como a política monetária atua na determinação da composição de portfólio de ativos dos agentes. Segundo o autor,

[...] é neste sentido que se constrói a pirâmide invertida que caracteriza a visão keynesiana da relação entre a moeda e os demais ativos financeiros [...] No vértice está a moeda legal, e sobre esse vértice se apóiam os outros ativos, em camadas sucessivas, definidas cada uma pelos arranjos institucionais que estabelecem as regras de conversibilidade entre os grupos [...] e pela relação entre as taxas de retorno obtidas em cada coleção de ativos." (Carvalho, 1994, p. 43-44).

É justamente por essa relação estabelecida entre os diversos ativos e a própria moeda que se concede à política monetária, por meio da gestão da taxa de juros, alguma capacidade de gerenciar a demanda efetiva e influenciar variáveis reais da economia. Contudo, em momentos de desconfiança generalizada, a política monetária pode pouco contribuir, haja vista a ilustração representada pela conhecida armadilha da liqui$d e z^{16}$. Por conta disto, Keynes, apesar de conceder significativa importância à condução da política monetária, argumenta que

\footnotetext{
${ }^{15}$ Cabe salientar que as alterações da taxa de juros de mercado podem depender apenas das expectativas dos agentes no mercado, os quais Keynes estilizou como bulls e bears. Bulls e Bears, a rigor, são os agentes que operam no mercado financeiro, especulando entre as bank rate e bond rate. Assim, a especulação altera a taxa de juros de mercado, influenciando as alocações de moeda entre poupança e investimento.

${ }^{16}$ Para informações sobre a armadilha da liquidez, veja: Krugman (2000).
} 
[...] não é muito correto que eu confira importância primaz à taxa de juros. Confiro importância primaz à escala de investimento e me interesso na taxa de juros como um dos elementos para se alcançar isto. Mas, devo considerar a intervenção estatal como encorajadora de investimento um fator mais importante. (CWJMK, XXVII, 1980, p. 350).

Pode-se acrescentar, ainda, a seguinte passagem da GT:

Encontrando-se o Estado em situação de exercer influência sobre a eficiência marginal dos bens de capital a longo prazo e com base nos interesses gerais da comunidade, espero vê-lo assumir a responsabilidade cada vez maior na organização direta dos investimentos (Keynes, 1964, p. 164, itálicos adicionados).

\subsection{A política fiscal}

A passagem acima leva à análise da política fiscal que, para Keynes, é a principal forma de intervenção estatal. Ela se ancora tanto na administração de gastos públicos - algo completamente diverso de déficit público - quanto na política de tributação e age diretamente sobre a demanda efetiva da sociedade.

A política de tributação, por um lado, deve viabilizar que a renda desigualmente distribuída da sociedade possa ser realocada, seja por tributação da renda, via sobretaxas, seja por impostos sobre a herança. Consoante Keynes (1964, p. 377), “é naturalmente inegável que uma política fiscal de altos impostos sobre heranças faz aumentar a propensão da comunidade a consumir". Por outro, ela fomenta, pela ampliação da capacidade de gasto do Estado, a expansão da demanda agregada da sociedade.

A administração dos gastos públicos para Keynes centra-se na constituição de dois orçamentos: o corrente e o de capital. O orçamento corrente diz respeito ao fundo de recursos necessários à manutenção dos serviços básicos fornecidos pelo Estado à população sob sua guarda, tais como saúde pública, educação, infraestrutura urbana e previdência social. Embora Keynes acreditasse na importância destes gastos correntes, mormente as transferências da previdência social, como esta- 
bilizadores automáticos dos ciclos econômicos, o orçamento corrente deveria ser sempre superavitário, no limite equilibrado.

Como ilustração dessa preocupação com o equilíbrio orçamentário, Keynes (CWJMK, XXVII, 1980, p. 204-205) argumenta que, no bojo dos debates que se travaram na Inglaterra sobre o sistema de Seguridade Social que deveria ser construído após a Segunda Guerra Mundial ${ }^{17}$, as pensões a serem pagas "constituir-se-iam em um severo fardo, ao ser necessário pagar pensões para as quais não havia fundos acumulados e, simultaneamente, acumular fundos para pensões futuras".

A necessidade de inibição de saldos deficitários no orçamento corrente decorre dos reflexos dos déficits públicos sobre uma economia monetária de produção, dentre os quais:

(i) a criação de dívidas de "peso morto" para as quais nada lucrativo foi constituído em contrapartida, para equilibrar seu pagamento futuro; (ii) a pressão sobre a taxa de juros da economia, em função da demanda por recursos privados pelo setor público para financiar seus saldos deficitários;

(iii) o risco de, a depender do ritmo de crescimento do endividamento e do perfil deste, em comparação com o crescimento econômico e com o aumento das receitas públicas, o Estado ficar refém de criar dívida nova para pagar dívida velha.

Diante disto, Keynes (CWJMK, XXVII, 1980, p. 278) infere que "[eu] não devo objetivar alcançar a compensação das flutuações cíclicas do sistema econômico por meio do orçamento corrente. Eu devo deixar esta tarefa ao orçamento de capital".

Para Keynes (CWJMK, XXVII, 1980), a outra parte do orçamento público, o orçamento de capital, é aquele em que se discriminam as despesas públicas referentes a investimentos produtivos levados a cabo pelo Estado para a manutenção da estabilidade no sistema econômico. Esses investimentos devem ser realizados por órgãos públicos ou semipúblicos ${ }^{18}$, desde que com objetivos claros de regulação do ciclo econômico por meio da

\footnotetext{
${ }^{17}$ As discussões se travaram principalmente, entre Keynes e William Beveridge. Para mais, veja Keynes (CWJMK, XXVII, 1980, p. 204-205).

${ }^{18}$ Para Keynes, o órgão semipúblico "busca o bem público [...] [e] aproxima-se mais do status de uma corporação pública do que de uma empresa privada”. [Como exemplo, tem-se] "as universidades, o Banco da Inglaterra e a Autoridade Portuária Londrina e [...] instituições joint-stock.” (Keynes apud Kregel, 1985, p. 37).
} 
ampliação do grau de crença racional dos empresários na demanda efetiva futura daquilo que eles, no presente, decidam empreender.

O orçamento de capital, por ser um indutor de instituições produtivas, é construtor de seu próprio superávit ao longo do tempo. Para o equilíbrio das finanças públicas, basta que, no curto prazo, não se incorra em déficit corrente, uma vez que os superávits demandados no orçamento corrente financiam eventuais déficits no orçamento de capital. Por outro lado, os retornos dos investimentos públicos realizados tendem a equilibrar, no longo prazo, o próprio orçamento de capital. Nas palavras de Keynes (CWJMK, XXVII, 1980, p. 320), que se configuram em outra regra para os policymakers, os "dispêndios de capital devem, no mínimo parcialmente, se não completamente, pagar a si mesmo".

Nesse particular, de forma bastante diversa do que o analista desavisado tem em mente ${ }^{19}$, a política de gasto público keynesiana tem como cerne o equilíbrio do orçamento em geral, ainda que no curto prazo isto possa ser alcançado via superávit no orçamento corrente e déficit no orçamento de capital. Mankiw (1991, p. 5), em seu artigo "The Reincarnation of Keynesian Economics", incorre em erro de interpretação da ideia de Keynes, ao afirmar, sem sequer dissertar sobre o orçamento bipartite keynesiano, que "o gasto deficitário é, portanto, bom para a economia". No mesmo texto, aponta Mankiw (1991, p. 8) que os policymakers devem ser livres para exercer suas discrições para alterarem as condições econômicas, e devem evitar a aderência a uma regra política rígida”.

Como visto, nas palavras do próprio Keynes, as políticas monetária e fiscal devem ser regradas, não somente para que seus efeitos não sejam adversos em relação aos objetivos da intervenção estatal, mas principalmente porque a política econômica é uma regra, uma convenção, sobre a qual se apoia o empresário. A regra de condução da política econômica é o que a viabiliza enquanto coordenadora da atividade econômica, dando peso ao argumento dos investidores. Se a atuação da política econômica fosse casuísta, ela simplesmente não funcionaria como fornecedora de premissas às proposições dos agentes, mas, pelo contrário, deixá-los-ia com bases ainda mais precárias sobre as quais decidiriam como agir, afinal, seria uma política fiscal que mudaria constantemente.

\footnotetext{
${ }^{19}$ Para uma série de aplicações inadequadas das políticas econômicas de Keynes - ou pretensamente keynesianas -, veja Skidelsky (1999, p. 133-140), além de Bresser-Pereira e Dalla'acqua (1991) e Gobetti (2008).
} 
Outra importante regra sobre a operacionalização do orçamento de capital refere-se ao fato de que os investimentos públicos nele arrolados não podem ser rivais, mas devem ser complementares aos investimentos da iniciativa privada (Carvalho, 1999). Ademais, estes investimentos, normalmente, estão relacionados às inversões tecnicamente sociais, que são aquelas "decisões que não são feitas por ninguém se o Estado não as fizer” (Kregel, 1985, p. 37).

Consoante Davidson (1991a, p. 32) "as decisões econômicas são feitas por homens que enfrentam um incerto e imprevisível futuro econômico e que se movem de um fixo e irreversível passado". Logo, o tempo importa, tanto em seu caráter expectacional quanto no histórico, como visto. Nesse sentido, sendo o tempo uma variável central para os indivíduos e para aquilo que eles relevam para decidir se agir ou não, a verdadeira política fiscal estabilizadora automática keynesiana não pode ter caráter de instrumento de última instância, ou seja, ela não deve ser posta em prática de forma casuísta, como último recurso disponível. Segundo Keynes, a tarefa do "estabilizador automático" é prevenir largas flutuações por intermédio de um programa estável e perene de investimentos de longo prazo. Nas palavras de Keynes (CWJMK, XXVII, 1980, p. 322), ser o Estado um "estabilizador automático" implica ele manter "um programa de longo prazo [de investimentos] que seja capaz de reduzir a amplitude potencial de flutuação para limites muito mais estreitos."

Não seria a função de o Estado socorrer um pico ou um vale de uma trajetória do sistema econômico, mas evitar que picos ou vales existam. Uma vez estabelecido este programa de longo prazo de investimentos produtivos, as flutuações que se apresentem no curto prazo são mais facilmente contornáveis por meio da antecipação de algumas medidas futuras, haja vista o surgimento dos primeiros sintomas de insuficiência de demanda efetiva, ou pelo postergar de algum projeto de investimento do orçamento de capital quando se percebam quaisquer sinais de excesso de demanda agregada.

Neste particular, portanto, as ações de contenção de flutuações no curto prazo não devem ser restritas a promover fases de expansão, mas devem ser requisitadas, inclusive, para evitarem-se episódios de excesso de demanda agregada. Como aponta Keynes, 
[...] decorre, então, que a maior quantidade de dinheiro, disponível para gasto, nos bolsos dos consumidores vai se deparar com uma quantidade de bens que não é aumentada [Assim] [...] o consumidor voltaria para casa com dinheiro a lhe queimar os bolsos [...] [de forma que] é preciso arranjar alguns meios de retirar do mercado o poder aquisitivo; senão [...] prevalecerá o método de inflação (Keynes apud Szmrecsányi, 1978, p. 194).

A forma pela qual Keynes concebe equilíbrio do saldo do orçamento de capital no longo prazo torna muito mais racional e viável o orçamento público em sua totalidade, fomentando ao longo do tempo a construção de superávits e, por conseguinte, de poupança pública, em ambas as partes do orçamento, o que sinaliza aos indivíduos maior capacidade de intervenção para o Estado atuar de forma cíclica. Torna-se, assim, ainda mais distante a incursão em déficits orçamentários que, conforme ratifica Keynes (CWJMK, XXVII, 1980, p. 352), advirá se “o volume de investimentos planejados falhar na produção do equilíbrio”. Nessas condições, e somente nelas,

[...] o equilíbrio [orçamentário] poderá ser encontrado por meio do desequilíbrio [...] do orçamento corrente. Admitidamente isto deverá ser um último recurso, que deverá entrar em jogo apenas se a maquinaria do orçamento de capital se quebrar. (CWJMK, XXVII, 1980, p. 352).

Não obstante, Keynes ainda argumenta que, para não restarem dúvidas quanto a sua verdadeira intenção ao prescrever regras de funcionamento à política fiscal, "então, decididamente [...] [não se deve permitir] que se confunda a ideia fundamental do orçamento de capital com o particular - e um tanto quanto desesperado - expediente do déficit" (CWJMK, XXVII, 1980, p. 353-354).

O papel fundamental dado ao gasto com o investimento vis- $a$-vis o gasto em consumo, em termos da dinâmica da demanda agregada em uma perspectiva keynesiana, concentra-se, em especial, sobre três aspectos.

Primeiramente, o estoque acumulado de riqueza na sociedade depende essencialmente das decisões de investimento dos empresários. Em segundo lugar, como destaca Carvalho (2008), o aumento inicial da riqueza, em decorrência da passagem de recursos de um indivíduo 
para outros no ato de investir, é capaz de gerar um circuito de gastos e, então, novos aumentos de renda por meio do efeito multiplicador dos investimentos. A multiplicação dos investimentos é uma âncora aos empresários uma vez que conforma peso em seus argumentos, ampliando seus estados de confiança em suas apostas em receitas futuras que remunerarão seus gastos efetivados. Por fim,

[...] a questão que surge diz respeito ao porque eu preferiria uma forte escala de investimento em relação a um crescimento no consumo. Minha principal razão sobre esse ponto é que eu não acredito que tenhamos alcançado o ponto de saturação do capital. Será do interesse do padrão de vida no longo prazo se crescermos largamente nosso capital (CWJMK, XXVII, 1980, p. 350).

Ademais, o investimento deve ser conduzido pela complementaridade entres as iniciativas privada e pública sendo que esta última, par excellence, deve funcionar como indutoras da primeira e, assim, como estabilizadora das flutuações cíclicas do sistema econômico. Não é demais salientar que as expectativas dos agentes são o fator desestabilizador do sistema e que, portanto, é sobre elas que atuará a política econômica keynesiana. Tão claro deve ser isso, principalmente aos empresários, que Keynes elabora a noção de orçamento de capital para que o investidor produtivo tenha compromissado consigo a atuação estatal como fornecedora de um maior grau de crença racional na demanda efetiva do sistema econômico.

Em um mundo incerto, no qual agentes arriscam sua possibilidade de comando sobre a riqueza a fim de conseguirem mais deste poder no futuro, a política econômica deve ser aquilo de mais sólido que a iniciativa privada tem contato, fomentando suas prospecções sobre o futuro e garantindo uma dinâmica de crescimento da riqueza. Sobre isto, Minsky (1986, p. 6) denota que

[...] se o mecanismo de mercado tiver que funcionar bem, nós devemos nos arranjar para constranger a incerteza devida aos ciclos de negócios, para que as expectativas que guiam os investimentos possam refletir a visão de um progresso tranquilo. 
Como aponta Marcuzzo (2005, p. 2, itálicos adicionados), a teoria de Keynes é um anúncio, a todo tempo, daquilo que precisa ser realizado para que "sustente-se o nível de investimento, mas isso deve ser interpretado mais no sentido de estabilizar a confiança dos negócios do que um plano para obras públicas financiadas por lançamento de dívida”. Isso porque

[...] a confiança de [Keynes] na socialização dos investimentos ao invés de em uma política fiscal objetivando a suavização dos níveis de consumo ao longo do ciclo de negócios mostra seu interesse sobre o tamanho do déficit; e, a importância atribuída aos incentivos dados ao mercado para alcançar-se o nível desejado de emprego (Marcuzzo, 2005, p. 2, itálicos adicionados).

Evidencia-se, enfim, que a política econômica keynesiana, tanto em sua concepção quanto em sua operacionalização, pretende a manutenção dos níveis de demanda efetiva, tendo como fim abrandar o desemprego involuntário, por meio da estabilização do estado de confiança dos homens de negócio. $\mathrm{O}$ resultado que se anseia chegar via políticas econômicas keynesianas é a construção de uma sociedade com uma trajetória que conte perenemente com eficiência econômica, justiça social e liberdade individual.

\section{Considerações finais}

$\mathrm{Na}$ GT, Keynes escreveu que "os principais problemas da sociedade econômica em que nós vivemos são o desemprego e a arbitrária e desigual distribuição da renda e da riqueza" (1964, p. 372). Tal citação expressa, de certa forma, a ideia central do capítulo, qual seja, mostrar que a visão de Keynes sobre a dinâmica operacional de economias monetárias, em uma realidade de organicismo social e de intervenção do Estado na economia, especificamente por meio de suas proposições de política monetária e fiscal, visavam, em grande parte, solucionar as crises de demanda efetiva e, por conseguinte, de desemprego, e distribuir a renda social entre as diversas classes sociais. Enfim, esse é o conteúdo filosófico e social da política econômica de Keynes. 
Keynes não queria que o capitalismo sucumbisse; muito pelo contrário, queria reformá-lo e salvá-lo. Para tanto, rejeitando o capitalismo à la laissez-faire, ele propõe um capitalismo regulado em que as disfunções do mercado fossem suprimidas pela intervenção do Estado para, por um lado, garantir e sustentar o pleno emprego e, por outro, atacar o excessivo grau de concentração de renda e de riqueza.

É a partir da intervenção do Estado na economia, seja por políticas públicas, seja através de ações de natureza normativa imprescindíveis para a construção de um ambiente institucional favorável às tomadas de decisão dos empresários, que Keynes sinaliza a reforma do sistema capitalista. Nesse particular, segundo O’Donnell (1989, p. 293), Keynes tinha em mente uma reforma do capitalismo em que "o objetivo final era a construção de uma utopia não-capitalista, muito mais próxima às sociedades comunistas ou utópicas de 'esquerda' do que às sociedades construídas sob a égide do capitalismo [liberal]".

Indo nessa direção, a partir de sua análise sobre a lógica operacional de economias monetárias, Keynes, ao longo de sua vida, apresentou inúmeras propostas de reformas do capitalismo, inclusive aquelas relacionadas à reestruturação do sistema monetário internacional (CWJMK, XXVII, 1980). Em comum a todas as proposições, a ideia de que o crescimento econômico sustentável e o desenvolvimento social devem consistir no esforço daqueles que não cometem os erros dos pessimistas, conforme escreveu Keynes em "Economic Possibilities for Our Grandchildren” (CWJMK, IX, 1972a, p. 322):

[...] existem os pessimistas revolucionários que pensam que
a situação é muitíssimo ruim e que nada pode solucioná-la a
não ser os atos de violência, e há os pessimistas reacionários
que consideram que a nossa situação econômica e social é
tão precária que não vale a pena arriscarmos mudanças.

Nesse particular, não é demais salientar que nem os erros dos pessimistas e tampouco o conformismo reacionário se constituíram em uma alternativa válida para Keynes. Assim, era válido para Keynes, e por isto sua filosofia da prática posta em ação por suas proposições reformistas e intervencionistas enquanto teórico e agente público do governo britânico, buscar transformar o capitalismo de mercado em capitalismo 
regulado para que se pudesse construir o tempo em que "o problema econômico não é - se olharmos para o futuro - o problema permanente da raça humana" (CWJMK, IX, 1972a, p. 326).

Dessa maneira, para finalizar, conforme Keynes esperava para "nossos netos", o objeto de desejo humano não mais seria a riqueza material concentrada nas mãos de poucos, mas desfrutada por toda a sociedade. Não por menos, Keynes ousou apontar que no longo prazo

[...] [n] os vejo livres, então, para retornar para alguns dos mais certos princípios da religião e da virtude tradicional - para os quais a avareza é um vício, a extorsão pela usura é uma transgressão, e o amor ao dinheiro é detestável [...] Eu enxergo à frente, para dias não tão remotos, como resultado, a maior mudança que já ocorreu no ambiente material em que vivem o conjunto da humanidade [...] [Nestes dias] permanecerá razoável ser economicamente proativo para os outros uma vez que já cessou ser razoável [ser proativo] para si (CWJMK, IX, 1972a, p. 330-331).

\section{Referências}

ANDRADE, R.P. A agenda do keynesianismo filosófico: origens e perspectivas. Revista de Economia Política, São Paulo, v.20, n. 2, p.76-94, 2000.

BATEMAN, B.W.; DAVIS, J.B. (Editors). Keynes and Philosophy: essays on the origin of Keynes's thought. Brookfield: Edward Elgar, 1991.

The rules of the road: Keynes's theoretical rationale for public police. In:

BATEMAN, B.W.; DAVIS, J.B. (Editors). Keynes and Philosophy: essays on the origin of Keynes's thought. Brookfield: Edward Elgar, p.55-68, 1991.

BRESSER PEREIRA, L.C.; DALLA'ACQUA, F. Economic populism versus Keynes: reinterpreting budget deficit in Latin America. Journal of Post Keynesian Economics, v,14, n.1, p. 19-38, 1991.

CARDOSO, F.; LIMA, G.T. A visão de Keynes do sistema econômico como um todo orgânico complexo. Economia e Sociedade, Campinas: Unicamp, v.17, n.3, p.359-381, 2008. CARVALHO, F.J.C. Keynes on probability, uncertainty and decision making. Journal of Post-Keynesian Economics, v.11, n.1, p.66-81, 1988.

Temas de política monetária keynesiana. Ensaios FEE, v.15, n.1, p.33-61, 1994. 
CARVALHO, F.J.C. Políticas econômicas para economias monetárias. In: LIMA, G.T.; SICSÚ, J.; PAULA, L.F. (orgs.). Macroeconomia Moderna: Keynes e a economia contemporânea. Rio de Janeiro: Campus, 1999. p. 258-281.

. Características essenciais do método de Keynes na teoria Geral. In: CORAZZA, G. Métodos da Ciência Econômica. Porto Alegre: UFRGS, 2003. p.175-188.

Equilíbrio fiscal e política econômica keynesiana. Análise Econômica, ano 26 n.50, p.7-25, 2008.

COATES, J. The Claims of Common Sense: Moore, Wittgenstein and the social sciences. Cambridge: Cambridge University Press, 1996.

DAVIS, J.B. Keynes and organicism. Journal of Post-Keynesian Economics, v.12, n.2, p.308-315, 1989-1990.

DAVISON, P. Money and the Real World. Londres: Macmillan, 1978.

. Controversies in Post Keynesian Economics. Brookfield: Edward Elgar, 1991a.

. Is probability theory relevant for uncertainty? A post Keynesian perspective. Journal of Economic Perspectives, ano 5, n. 1, p.129-143, 1991 b.

EICHNER, A.S.; KREGEL, J. An essay on post-Keynesian theory: a new paradigm in economics. Journal of Economic Literature, v.13 n.4, p.1293-1314, 1975.

FERRARI FILHO, F. As concepções teórico-analíticas e as proposições de política econômica de Keynes. Revista de Economia Contemporânea, v.10, n.2, p.213-236, 2006.

GOBETTI, S. Tópicos Sobre a Política Fiscal e o Ajuste Fiscal no Brasil. Tese de Doutorado apresentada junto ao Programa de Pós-graduação em Economia da Universidade de Brasília. Brasília: 2008. 213p.

KATES, S.. The true meaning of Say's Law. Eastern Economic Journal, v.28 n.2, p. 191-202, 1992.

KEYNES, J.M. The General Theory of Employment, Interest and Money. New York: HBJ Book, 1964.

A Treatise on Money: The Pure Theory of Money. The Collected Writings of John Maynard Keynes, volume V. London: Royal Economic Society, 1971.

Essays in Persuasion. The Collected Writings of John Maynard Keynes, volume IX. London: Royal Economic Society, 1972a.

Essays in Biography. The Collected Writings of John Maynard Keynes, volume X. London: Royal Economic Society, 1972b.

. Treatise on Probability. The Collected Writings of John Maynard Keynes, volume VIII. London: Royal Economic Society, 1973a.

The General Theory and After: Defence and Development. The Collected Writings of John Maynard Keynes, volume XIV. London: Royal Economic Society, 1973b.

. The General Theory and After: A Supplement. The Collected Writings of John Maynard Keynes, volume XXIX. London: Royal Economic Society, 1979. 
KEYNES, J.M.Activities 1940 - 1946: Shaping the Post-War world: The Clearing Union. The Collected Writings of John Maynard Keynes, volume XXVII. London: Royal Economic Society, 1980.

KING, J.E. The Elgar Companion to Post-Keynesian Economics. Brookfield: Edward Elgar, 2003.

KREGEL, J. Economic methodology in the face of uncertainty: the modeling methods of Keynes and the post-Keynesians. The Economic Journal, v.86, n. 342, p.209225, 1976.

Budget deficits, stabilisation policy and liquidity preference: Keynes's PostWar policy proposals. In: VICARELLI, F. (ed.). Keynes's Relevance Today. London: Macmillan, p.28-50, 1985.

The viability of economic policy and the priorities of economic policy. Journal of Post Keynesian Economics, 17(2), p.261-277, 1994-1995.

KRUGMAN, P. Thinking about the liquidity trap. Journal of the Japanese and International Economies, v.14, 2000. p.221-237

. How economists get it so wrong? The New York Times. sept. 2, 2009. Disponível em: <http://www.nytimes.com/2009/09/06/magazine/06Economic-t.html>. LUCAS, R. Jr. The death of Keynesian economics. Issues and Ideas. Chicago, IL: University of Chicago. Winter, p.18-19, 1980.

MARCUZZO, M. C. Keynes and the Welfare State. Roma: Università di Roma. Disponível em: <http://www2u.biglobe.ne.jp/ olympa/Cambridge/hyoushi/marcuzzo. doc>. Acesso em: set. 2009, 2005.

MANKIW, N.G. The reincarnation of Keynesian economics. NBER Working Papers Series, n. 3885, Cambridge: NBER, 1991.

. What would Keynes have done? The New York Times, nov 28, 2008. Disponível em: < http://www.nytimes.com/2008/11/30/business/economy/30view.html>.

MINSKY, H. Stabilizing an Unstable Economy. New Heaven: Twentieth Century Fund Report, 1986.

MORENO, A.R. Wittgenstein e os labirintos da linguagem: ensaio introdutório. São Paulo: Moderna, 2006.

O’DONNELL, R.M. Keynes: philosophy, economics and politics. New York: St.Martin's Press, 1989.

ROBINSON, J. The second crisis of economic thought. The American Economic Review, v. 62, n,1-2, p.1-10, 1972.

ROTHEIM, R. J. Organicism and the role of individual in Keynes's thought. Journal of Post-Keynesian Economics. V.12, n.2, p.316-326, 1989-1990.

SKIDELSKY, R. Keynes. Rio de Janeiro: Jorge Zahar Editor, 1999.

SZMRECSÁNYI, T. Keynes. In: FERNANDES, F. (Org.) Coleção Grandes Cientistas Sociais, nº 6. São Paulo: Ática, 1978. 